\title{
HISTORIA Y POESÍA: EL MITO DE PÍRAMO Y TISBE EN EL «QUIJOTE»
}

\section{LOS MITOS CLÁSICOS EN EL RENACIMIENTO}

La influencia de la fábula mitológica de origen latino es muy extensa en Europa, sobre todo a partir del Renacimiento; tanto en las artes plásticas como en el orbe literario y poético. Numerosos estudios modernos analizan y ponderan sus múltiples facetas y manifestaciones.

Highet, en dos nutridos volúmenes, ha trazado un panorama general de los distintos modos en que la influencia griega y latina ha moldeado las literaturas de la Europa occidental (principalmente la inglesa y la francesa) y la de los Estados Unidos de América ${ }^{1}$.

Según el historiador Arnold Toynbee, la historia, como el drama y la novela, es hija de la mitología: una forma particular de comprensión y de expresión, donde -igual que en los cuentos de hadas de los niños y en los sueños de los adultos- no hay línea de demarcación entre lo real y lo imaginario.

Dejemos aparte ahora las relaciones del mito con el lenguaje humano en sí, razonadas en las teorías filológicas y filosóficas de Max Müller y de Ernst Cassirer; o la trascendencia poética del mito, defendida por Ortega y Gasset.

$\mathrm{Ni}$ nos interesan de momento los sentidos literal, alegórico, tropológico y natural que se pueden desmenuzar en la fábula mitológica. Tal fue la tarea del bachiller Pérez de Moya en su di-

1 Vid. GILBERT Highet, La tradición clásica. Influencias griegas y romanas en la literatura occidental. Traducción de ANTONio Alatorre. México, Fondo de Cultura Económica, 1954, 2 vols. 
latada Philosofía secreta, publicada en 1585, el mismo año en que aparecía La Galatea de Cervantes ${ }^{2}$.

Lo que ahora nos importa es subrayar la importancia que adquieren las fábulas de la antigua mitología grecorromana como venero de inspiración de la poesía española y europea, singularmente a partir del siglo XVI, y su brillante pujanza en la Edad de Oro de nuestras Letras.

Orfeo, Ulises, Ariadna, Apolo y Dafne, junto a otras figuras mítico-simbólicas, aparecen repetidamente en los poemas y prosas de los autores más celebrados. Desde Garcilaso de la Vega, Aldana o Juan de Arguijo, hasta Góngora, Quevedo y Bocángel; aunque es notoria la degradación burlesca de los temas mitológicos en el período barroco de los últimos poetas aducidos.

Las Metamorfosis de Ovidio han sido hiperbólicamente denominadas como la «Biblia del Renacimiento», en su original recreación y difusión de la arcaica fábula mitológica. Rudolf Schevill analizó la influencia ovidiana en la poesía española del Siglo de Oro. La estudió en un libro de principios de siglo, que todavía es aprovechable en su mayor parte ${ }^{3}$.

Entre la tupida floresta de los mitos clásicos, puede advertirse cierta predilección cervantina por la fábula de Píramo y Tisbe, recordada o aludida en tres pasajes del Quijote: dos en la Segunda Parte, bastante próximas y cuidadas, y otra más difusa y lejana en la Primera. No se han estudiado en su conjunto, más bien enaltecedor. Solamente han merecido ligeras aclaraciones y alguna aproximación de los comentaristas del Quijote, desde Clemencín a nuestros días, con Vicente Gaos en destacado lugar.

El profesor Ruiz de Elvira, en su cuidada edición de Ovidio, anota que el relato de Píramo y Tisbe (Metamorphoseon, lib. IV, vv. 55-166) es de los que han ejercido "perdurable influencia en la

2 Cfr. Juan Pérez de Moya, Philosofía secreta / donde debajo de historias fabulosas / se contiene mucha doctrina / provechosa a todos estudios. / Con el origen de los ídolos / o dioses de la gentilidad. /.../ Madrid, Francisco Sánchez, M.D.LXXXV.

A continuación del largo título descriptivo hay una advertencia cabal y pertinente: «Es materia muy necesaria para entender poetas y historiadores».

En su edición de esta obra en 1928, Gómez de Baquero define la Philosofía secreta como un tratado de mitología grecorromana escrito con el espíritu de los Diccionarios de la fábula, es decir, en el sentido de la ilustración humanística de la literatura antigua; pero también con el intento de sacar una enseñanza moral de las fábulas del mundo clásico. Como hombre de la Iglesia (eclesiástico consciente postridentino) utiliza los dioses antiguos con fines moralizadores.

Una edición reciente y muy recomendable de la Philosofía secreta es la de CARLOS Clavería, con extensa Introducción y 1.287 notas, en la colección de Letras Hispánicas (Madrid, Cátedra, 1995, 662 pp.).

3 Vid. RudOLF SCHEVILL, Ovid and the Renaissance in Spain. Berkeley, University of California Press, 1913. 
tradición clásica», como precedente de los enamorados Romeo y Julieta, inmortalizados por Shakespeare (que también rememora a Píramo y Tisbe en Midsummer Night's Dream). Y puntualiza que el mito de Píramo y Tisbe no es conocido por fuentes poéticas anteriores a Ovidio ${ }^{4}$.

Cervantes pudo conocer la fábula no sólo por las traducciones ovidianas de su tiempo, sino por las variadas creaciones poéticas inspiradas en ella durante el fecundo Siglo de Oro.

Montero Reguera ha destacado el sobrenombre de "Ovidio español», adoptado por el mismo Cervantes, tanto en su propia autoestimación cuanto en laude del celebrado poeta latino ${ }^{5}$.

En los versos preliminares del Quijote de 1605 figura un soneto atribuido a Gandalín, escudero de Amadís de Gaula, en elogio de Sancho Panza, escudero de Don Quijote, y se proclama en el último terceto:

\footnotetext{
Salve otra vez, ;oh Sancho!, tan buen hombre, que a solo tú nuestro español Ovidio, con buzcorona te hace reverencia.
}

Por otra parte, el primo que sirve de guía a Don Quijote para llegar a la cueva de Montesinos (II, 22) se nos presenta como imitador del poeta latino a lo burlesco, en su Metamorfosis u Ovidio español, «de invención nueva y rara...».

Y en la novela ejemplar de La ilustre fregona, leemos con respecto al cambio de indumento y profesión de los protagonistas, en el mesón de Toledo: "He aquí tenemos ya —en buena hora se cuente- a Avendaño hecho mozo del mesón, con nombre de Tomás Pedro, que así dijo que se llamaba, y a Carriazo con el de Lope Asturiano, hecho aguador; transformaciones dignas de anteponerse a las del narigudo poeta» ${ }^{6}$. Tales transformaciones son clara alusión a las metamorfosis y lo del "narigudo poeta» es una broma onomástica a costa de Publio Ovidio Nasón. El juego burlesco de Nasón como «narigudo» o «narizotas», lo había de confirmar Quevedo en el conocido soneto «Érase un hombre a una nariz pegado...», pues

4 Vid. P. Ovidio Nasón, Metamorfosis. Texto revisado y traducido por ANTONio RUIZ DE ElviRA... volumen I (Lib. I-V). Barcelona, Ediciones Alma Mater, S. A., MCMLXIV. (De las "cuestiones literarias» que atañen a la obra se nos informa en una Introducción (pp. ix-xxxiv), y en unas notas adicionales, al final del volumen (pp. 191-240).

5 Vid. José Montero Reguera, «Miguel de Cervantes: el Ovidio español», Studia Aurea, Actas del III Congreso de la AISO. Toulouse, 1993, III. Prosa, pp. 327-334.

6 Vid. Miguel De CERvantes, Novelas Ejemplares, III. Edición, introducción y notas de Juan Bautista Avalle-Arce. Madrid, Clásicos Castalia 1982, p. 68. 
el segundo cuarteto define al satirizado como «un Ovidio Nasón mal narigado» ${ }^{7}$.

Esta familiaridad de nuestros autores clásicos con el nombre y apelativos del autor de las Metamorfosis pone bien de manifiesto la popularidad y difusión del poeta latino en la cultura literaria española del Siglo de Oro.

\section{PíRAMO Y TISBE EN LA LITERATURA CLÁSICA ESPAÑOLA}

Píramo y Tisbe son figuras estimadas como prerrománticas en la apreciación de Dámaso Alonso, lo mismo que las de Hero y Leandro, "ya que desde el comienzo del mundo están unidos el amor y la muerte» ${ }^{8}$.

Basta con hojear rápidamente el grueso volumen de Cossío, acerca de las Fábulas mitológicas en España, para apreciar la general estimación de nuestros más destacados poetas del Siglo de Oro por los trágicos amores de la pareja babilónica. Entre las fábulas estudiadas por Cossío en esta dirección cabe destacar: en serio, las de Cristóbal de Castillejo, Jorge Montemayor, Gregorio Silvestre, Tirso de Molina y Antonio de Villegas; y en la modalidad burlesca o jocoseria, las de Góngora, «Pedro Silvestre», Miguel Efrén y Quevedo, Antonio González de la Reguera y Vicente García.

En consecuencia, aparte del modelo ovidiano, varias veces traducido en aquel tiempo, pudo acercarse Cervantes al mito de Píramo y Tisbe en alguna de las múltiples versiones que lo evocaron en nuestra poesía clásica. No podemos olvidar que la Diana de Montemayor, criticada con agridulce tono en el «donoso escrutinio» de la biblioteca del ingenioso hidalgo $(D Q, I, 6)$, relata la historia de Belisa (lib. $3 .^{\circ}$ ), relacionada con la leyenda de Fedra y la de Píramo y Tisbe. El interés de Montemayor por la segunda le llevó a escribir una versión poemática aparte, incorporada más tarde al texto de la Diana como apéndice, desde la edición de Valladolid en 1561; y con él fue difundida durante más de dos siglos ${ }^{9}$.

Nos proponemos dilucidar seguidamente la fortuna alcanzada por el mito de Píramo y Tisbe en las páginas del Quijote; y en tono

7 Vid. Francisco de Quevedo, Obras Completas, I, Poesía original. Edición, introducción, bibliografía y notas de José MANUEL BLECUA. Barcelona, Editorial Planeta, 1963, p. 562.

8 Vid. DÁmASO ALONSO, en su prólogo, «Primavera del mito», que abre el abultado volumen de las Fábulas mitológicas en España, reunidas por JosÉ M. ${ }^{a}$ DE Cossío (Madrid, Espasa-Calpe, 1952, p. xiii).

9 Cfr. JoRge DE MONTEMAYOR, La Diana. Edición, prólogo y notas de J. MonTERo. Barcelona, Ed. Crítica, 1996, pp. 140 y 162. 
creciente, puesto que de la simple mención recordatoria en la Primera Parte, se llega a la recreación de la misma fábula en dos momentos de la Segunda, bien con acendrado énfasis en sus tópicos de tragedia, bien con desenlace feliz de comedia optimista.

Son tres los pasajes que rememoran o renuevan el contenido de la fábula ovidiana: la historia de Cardenio y Luscinda en la Primera Parte del Quijote; en la Segunda, el soneto de don Lorenzo Miranda, hijo del llamado Caballero del Verde Gabán; y como restauración eufórica, el episodio de las bodas de Camacho, con la inversión cómica y placentera de los trágicos amores funestos.

\section{LUSCINDA, UNA TISBE INDECISA Y FUGITIVA}

Cardenio encarna una de las «locuras de amor» más inquietantes del primer Quijote (I, 23-24).

Trastornada su mente por la aparente traición de la amada Luscinda, y convertido en el "Roto de la Mala Figura», cuenta su desgracia a Don Quijote, "Caballero de la Triste Figura», en un agreste rincón de Sierra Morena: «Creció la edad y con ella el amor de entrambos; al padre de Luscinda le pareció que por buenos respetos estaba obligado a negarme la entrada de su casa, casi imitando en esto a los padres de aquella Tisbe tan decantada de los poetas...» $(D Q, 1,23)$. Nótese el énfasis en la mención, un tanto gratuita, de la mítica enamorada en la antigua Babilonia.

Clemencín, el primer comentarista importante del Quijote, ya reparó en la inadecuación del paralelismo establecido por Cervantes: «se hace mención de Píramo y Tisbe, cuyos amores cantó Ovidio, entre los antiguos; y varios modernos, antes y después de la era de Cervantes. La comparación que con ellos hace Cardenio de los suyos no es muy exacta, porque en los de Cardenio", como dice a continuación, "callaron las lenguas y hablaron las plumas, y no fue así en los de Píramo y Tisbe» ${ }^{10}$.

En efecto, el relato se refiere al apasionado intercambio epistolar de los enamorados, según el modelo estilístico de la novela sentimental, género iniciado a finales del siglo XV y descollante, sobre todo en el XVI, con la gran difusión de la Cárcel de amor de Diego de San Pedro.

En la historia de Cardenio, la mayor y casi única semejanza con la fábula ovidiana es la extrema y ponderada belleza y atractivo de

10 Vid. Cervantes, El ingenioso hidalgo Don Quijote de la Mancha. Edición IV Centenario, adornada con 356 grabados de Doré, enteramente comentada por Clemencín... Madrid, Ediciones Castilla (1947), p. 1236. 
los dos enamorados y la pasión amorosa que los enciende, dificultada por la autoridad paternal. En palabras de Ovidio:

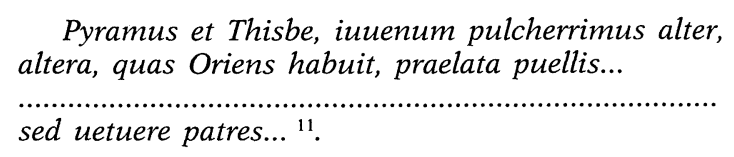

Lo cierto es que Píramo y Tisbe quedan muy al fondo del relato de Cardenio, como la pareja de arquetipos de jóvenes enamorados, a quienes pretende separar la familia. Se difumina el recuerdo poético de unos amores lejanos de signo fatal.

Cardenio y Luscinda, tras la desventura inicial, promovida por el libertino don Fernando, podrán ver la realización de sus mutuos anhelos con la firme promesa matrimonial (I, 36). El reencuentro en la venta del camino es una escena conmovedora y lacrimosa, pero con la brillante esperanza del desenlace feliz; más de comedia matrimonial que de novela sentimental de aquel tiempo.

\section{EL «CONSUMADO» SONETO DE DON LORENZO MiRANDA}

El episodio de don Diego de Miranda, más conocido como el Caballero del Verde Gabán, encierra alguna de las páginas más sustanciosas y controvertidas de todo el Quijote (II, 16-18). Desde Marcel Bataillon, que consideraba al personaje como el ideal erasmista de piedad laica y honradez esencial, hasta los que han reprochado al personaje sus precauciones de vida inerte o paralítica (Américo Castro), e incluso le encuentran una posible significación bufonesca (Márquez Villanueva). Toda una polifacética gama de interpretaciones para descifrar el papel de este caballero y su contraste funcional en la historia. Últimamente, Augustin Redondo, en su macizo estudio Otra manera de leer el Quijote (Madrid, Castalia, 1997), ofrece una nueva y atractiva visión del Caballero del Verde Gabán, basada en consideraciones de tipo histórico, onomástico y religioso.

Por mi parte, hace muchos años le dediqué un detenido ensayo, en el que destacaba la «dorada medianía» que circunda al sedentario manchego y la recepción doméstica con la que invita al animoso Caballero de los Leones con gran simpatía, sin ulteriores burlas ni sarcasmos ${ }^{12}$.

\footnotetext{
11 Es el comienzo de la fábula de Ovidio: Metamorphoseon, lib. IV, vv. 55-56 y 61. Cito según la edición indicada en la nota 4 . Todas las referencias que hagamos al original latino proceden de la misma edición.

12 Cfr. AlBerto SÁnCHEZ, "El Caballero del Verde Gabán», Anales Cervantinos, IX, 1961-1962, pp. 169-201.
} 
De los tres capítulos que integran el episodio completo, nos interesa ahora especialmente el último (II, 18) y sólo en su parte final.

Precisamente, don Lorenzo Miranda, hijo del Caballero del Verde Gabán y estudiante en la prestigiosa Universidad de Salamanca, se nos muestra más aficionado a la poesía que a las Humanidades y estudios jurídicos, a que le inclinaba su padre.

A requerimientos del huésped, recita a Don Quijote algunas de sus poesías originales. Concretamente, una glosa octosilábica sobre la herida del tiempo fugitivo y un soneto inspirado en la «fábula o historia» de Píramo y Tisbe. Interesa transcribirlo en su integridad para apreciar la aguda síntesis de la tragedia de los dos enamorados que sólo conseguirán unir sus restos en la urna funeraria donde reposarán perdurablemente:

quodque rogis superest, una requiescit in urna ${ }^{13}$.

El soneto dice así:

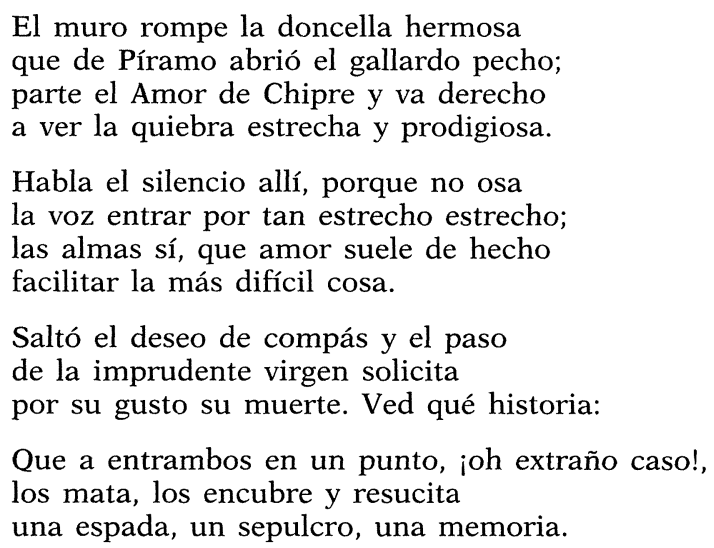

Que a entrambos en un punto, ¡oh extraño caso!, los mata, los encubre y resucita una espada, un sepulcro, una memoria.

(DQ, II, 18)

La exaltación del caballero al escuchar estos versos nos revela la intención desmitificadora del poema: "¡Bendito sea Dios!», dijo Don Quijote habiendo oído el soneto a don Lorenzo, «que entre los infinitos poetas consumidos que hay, he visto un consumado poeta, como lo es vuestra merced, señor mío, que asi me lo da a entender el artificio de este soneto".

La festiva paronomasia de consumido y consumado no desveló a Clemencín el verdadero alcance de la parodia estilística y juzgó

13 Vid. Met., l. IV, v. 165, obra cit. en las notas 4 y 11 . 
el juicio de nuestro caballero como otra cándida alabanza de Cervantes a sus propios versos; para añadir que el único soneto bueno que salió de la pluma cervantina fue el dedicado al túmulo de Felipe II en la catedral de Sevilla («honra principal de mis escritos», según lo calificó razonablemente en el Viaje del Parnaso). También trae a colación Clemencín otras composiciones del Siglo de Oro sobre el tema de Píramo y Tisbe, como las mencionadas de Cristóbal de Castillejo, Jorge de Montemayor y Góngora.

Cita asimismo un soneto de Lope de Vega (el 18 de Rimas humanas) que "vale tan poco como el de don Lorenzo de Miranda» ${ }^{14}$. Añade algunas consideraciones acerca de la dificultad que encierra la composición de un buen soneto y resume en pocas líneas la historia de esta composición poética. Nos advierte que Lope de Vega «publicó muchísimos, pero entre todos hay muy pocos buenos». Por supuesto, los críticos contemporáneos (Menéndez Pelayo, Entrambasaguas, Dámaso Alonso, Gerardo Diego) tienen un aprecio bastante más elevado de la poesía de Lope de Vega.

Hemos de insistir en la rebuscada afectación estilística del soneto de don Lorenzo como indicio posible de la intención paródica que habíamos advertido.

Ya en el primer cuarteto, la delgada grieta en el muro medianero que separa las casas contiguas de los enamorados, se convierte en la «quiebra estrecha y prodigiosa», intensificada después en el "estrecho estrecho», con duplicación intensiva de un simple defectillo en la construcción. Ovidio lo había declarado con más elegante sobriedad:

Fissus erat tenui rima, quam duxerat olim,

cum fieret, paries domui communis utrique... ${ }^{15}$.

Hay alambicadas y sutiles expresiones, como «habla el silencio alli» 16 , junto a otras más comunes (el amor obliga a "facilitar la más difícil cosa»), o la aliteración menos frecuente de "saltó el deseo de compás y el paso / de la imprudente virgen.... ${ }^{17}$.

14 Vid. Cervantes, Don Quijote, en la edición señalada en la nota 10, p. 1620.

15 Vid. Ovidio, edición citada, l. IV, vv. 65-66.

16 Cfr. mi trabajo, citado en la nota 12 , pp. $198-200$

17 Sobre la elocuencia del silencio - valga la paradoja- en el Quijote, se ha dicho bastante por la crítica. Añadiremos ahora el "maravilloso silencio" de la casa del Caballero del Verde Gabán, que tanto agradó a su huésped (II; 18), y dos ejemplos muy notables de los últimos capítulos de la obra: "El silencio fue allí el que habló por los amantes y los ojos fueron las lenguas que descubrieron sus alegres y honestos pensamientos" (II, 65); «en aquel sitio el mesmo silencio guardaba silencio a sí mismo» (II; 69) o la apoteosis del silencio. 
Para cerrar el soneto con el exaltado epifonema de los dos últimos endecasílabos, de correlación trimembre:

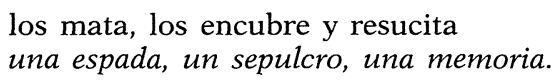

Obsérvese la particular resonancia antitética del muy celebrado soneto imperial de Hernando de Acuña: Un monarca, un imperio y una espada. En mi juvenil ensayo sobre el Caballero del Verde Gabán, al que me he referido anteriormente, hacía un análisis del soneto cervantino y daba una hipótesis bastante arriesgada de la posible significación simbólica del mismo. Pero su explicación, como una síntesis esencial de la fábula ovidiana, queda del todo diáfana en la trimembración del último verso.

Solamente perdura la espada; es decir, la violencia, la muerte, la destrucción. En cuanto al mismo sepulcro, que une para siempre a los dos fieles amantes, es un traslado fiel del propio Ovidio, según hemos adelantado: una requiescit in urna (v. 166). En cuanto a la memoria de la doble inmolación, queda muy reforzada para siempre en los múltiples reflejos de la fábula de Ovidio (incluida la versión de don Lorenzo).

\section{DE LAS BODAS DE CAMACHO EL RICO A LAS DE BASILIO EL POBRE}

Por otra parte, el soneto comentado sirve de lema premonitorio al episodio que se cuenta en los tres capítulos siguientes del Quijote (II, 19, 20 y 21). En los título de los tres se repite el vocablo sucesos en la acepción neutra que entonces tenía: suceso es lo que sucede, sea bueno o malo. Aunque en el castellano actual se inclina más hacia lo trágico, novelesco e incluso catastrófico (lo opuesto al succès de la lengua francesa, o al success del inglés, que denotan éxito o triunfo).

Repasemos las aludidas rúbricas: "Cap. XIX - Donde se cuenta la aventura del pastor enamorado, con otros en verdad graciosos sucesos", "Cap. XX - Donde se cuentan las bodas de Camacho el rico con el suceso de Basilio el pobre» y "Cap. XXI Donde se prosiguen las bodas de Camacho, con otros gustosos sucesos». La misma significación de los epítetos, graciosos y gustosos, nos lleva a la consideración de un desenlace feliz y halagüeño, como cabía esperar de la significación etimológica del término suceso. Durante el Siglo de Oro, el lexicógrafo Covarrubias equipara dos vocablos hoy un tanto divergentes: suceso vale como acaecimiento. 
El compromiso familiar de la boda campestre de Camacho el rico y la hermosa Quiteria viene a torcer el destino de Basilio el pobre, pues no tenía "tantos bienes de fortuna como de naturaleza».

Se evoca el mito clásico en sus peculiares circunstancias: «Es este Basilio un zagal vecino del mesmo lugar de Quiteria, el cual tenía su casa pared y medio de la de los padres de Quiteria, de donde tomó ocasión el amor de renovar al mundo los ya olvidados amores de Píramo y Tisbe; porque Basilio se enamoró de Quiteria desde sus tiernos y primeros años, y ella fue correspondiendo a su deseo con mil honestos favores»... (II, 19).

Pero el padre de Quiteria le impone la boda con Camacho para mejorar su posición. Nótese la fidelidad al mito poético en sus comienzos y planteamiento: la vecindad de la pareja (continuas tenuere domos), acrecentamiento del amor con el tiempo (tempore creuit amor) y la oposición paterna al matrimonio de los enamorados (sed uetuere patres). Sobreviene el conflicto, que Cervantes ha imaginado solucionar pacíficamente, después de asustarnos con el simulado suicidio de Basilio ante los preparativos ostentosos de la boda de Camacho. El desesperado mancebo finge suicidarse para lograr su propio enlace in articulo mortis, sin trámites preparatorios y con la mayor rapidez, ante la obligada y sorpresiva aquiescencia del novio oficial, Camacho el rico. Triunfa así el Amor sobre el Interés, a pesar de lo significado en la danza simbólica que acompaña al jolgorio campesino. Recibida la bendición sacerdotal por los inesperados contrayentes, se pone de manifiesto la industria (que no milagro) o traza ingeniosa del fingido suicida para conseguir su propósito.

Don Quijote apoya la decisión de Basilio, después de cambiar ostensiblemente su teoría tradicional contra la libertad y voluntad de los contrayentes y de respeto a la autoridad paterna.

$\mathrm{Su}$ argumento definitivo es un tanto maquiavélico en esencia: alcanzar el triunfo sin reparar en medios. Tales son sus razones: «el amor y la guerra son una misma cosa, y así como en la guerra es cosa lícita y acostumbrada usar de ardides y estratagemas para vencer al enemigo, así en las contiendas y competencias amorosas se tienen por buenos los embustes y marañas que se hacen para conseguir el fin que se desea» (II; 21).

Pero el razonamiento desemboca en una contradicción flagrante: "Camacho es rico y podrá comprar su gusto cuando, donde y como quisiere. Basilio no tiene más de esta oveja y no se la ha de quitar alguno por poderoso que sea»(II, 21). La evidencia nos impone aquí lo contrario: las bodas de Camacho el rico se han convertido en las de Basilio el pobre, con la frustración dolosa de la voluntad del primero. 
El propio Sancho también experimenta un sensible cambio en su opinión primeriza, motivado ahora por la glotonería, que le había inclinado a defender el dicho vulgar de «tanto vales cuanto tienes y tanto tienes cuanto vales». Por supuesto, no puede ser alabada en este caso su discreción, como fue exaltada entonces la de Don Quijote, "teniéndole por un Cid en las armas y por un Cicerón en la elocuencia» (II, 22). No la decantada antítesis de armas y letras, sino la conjunción armoniosa y emblemática.

Don Quijote está en la cumbre de su personal apogeo. Se ha convertido en el Caballero de los Leones desde la semana anterior (II, 17), apelativo de mayor preeminencia que el de Caballero de la Triste Figura, como le había denominado su propio escudero, en la aventura del cuerpo muerto de su segunda salida (I, 19).

Es más, su discurso en defensa de Basilio, sin posible réplica, viene a otorgarle la plenitud de su intervención en defensa del más débil y aquí se apoya la única justificación de su actitud.

$\mathrm{La}$ abundancia de Camacho el rico es vencida por la industria ingeniosa de Basilio el pobre. Que ahora no es el pobre Basilio, sino el afortunado. En la interpretación de Casalduero se concluye por admitir que "la industria y la destreza vencen a la fuerza, a la riqueza y a la naturaleza». La Naturaleza debe quedar sometida a un principio superior ${ }^{18}$.

De todas formas, no conviene olvidar que Cervantes, a partir de una fábula conocida desde la Antigüedad y que terminaba con el doble suicidio de los enamorados (trágico fatalismo), se permite transformar el desenlace, gracias a la libertad de los modernos amantes, para terminar en la gran fiesta de la boda campesina.

Fiel a un antideterminismo de raíz estoica, Cervantes repite en muchas de sus creaciones literarias que cada cual se fabrica su destino: "Tú mismo te has forjado tu ventura» y "Cada uno se fabrica su ventura», se reitera en el Viaje del Parnaso (IV); «cada uno es el artífice de su fortuna desde el principio hasta el cabo" (Persiles, lib. 4. ${ }^{\circ}$, I)... Y Basilio no podía ser menos.

Para Lapesa este desenlace, desviadamente feliz, de las ponderadas bodas de Camacho y su apuesta por la vida y el amor de Basilio (con olvido de la muerte y la unión en el sepulcro) demuestra una vez más el optimismo vital cervantino frente a las contrariedades del mundo.

Parte nuestro gran filólogo de una difícil confrontación establecida por Helmut Hatzfeld entre Góngora y Cervantes, a propósito

18 Cfr. Joaquín Casalduero, Sentido y forma del Quijote (1605-1615). Madrid, Edics. Ínsula, 1949, pp. 259-269. 
de las bodas campestres de la Soledad I y las de Camacho en la Segunda Parte del Quijote ${ }^{19}$.

Lapesa amplía los paralelos de coincidencia temática en los dos escritores clásicos, Góngora y Cervantes: así, el tópico del soldado fanfarrón o la penuria del hidalgo, las adaptaciones de los romances viejos de Durandarte y Belerma, junto a los de Gaiferos y Melisendra, etc. Sin que podamos olvidar la dúplice proyección, noble y ridícula, de la Fábula de Píramo y Tisbe en octosílabos gongorinos.

Recordaremos, ante todo, dos romances: el primero, breve y digno ( $D$ De Píramo y Tisbe quiero, / si quisiere mi guitarra, / contaros la historia, ejemplo / de firmeza y de desgracia»...); pero el segundo, muy dilatado, prolijo y grotesco, con mención del poeta latino, difundida y burlona:

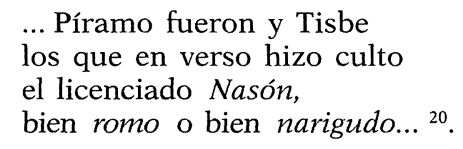

Lapesa termina su confrontación mediante afirmaciones convincentes: «el dinamismo de Cervantes responde a su fe en la vida... El reconocimiento de la vida como buen don de Dios infundió a Cervantes un fundamental optimismo capaz de sobreponerse a injusticias, amarguras y fracasos le llevó a buscar en cada ser humano la centella salvadora, a aceptar la realidad y a tomarla como su nivel literario preferido. Góngora, receloso ante la vida, no trató de reflejarla; insatisfecho de la realidad, la pintó en sus aspectos más deleznables y viles. $\mathrm{O}$ se evadió de ella huyendo al mundo de las perfecciones soñadas» ${ }^{21}$. Admitido este supuesto, la transfiguración de Píramo en Basilio no podía tener un fin trágico y desconsolador, sino feliz y dichoso. En la pugna vital del Interés y el Amor, había de triunfar el Amor por decisión poética, de categoría superior a la circunstancia histórica.

19 Vid. RAFAel LAPESA, "Góngora y Cervantes: coincidencia de temas y contraste de actitudes", en De la Edad Media a nuestros días (Madrid, Ed. Gredos, 1967, pp. 219-241).

20 Cfr. Luis DE GÓNGORA Y ARGOTE, Obras completas. Recopilación, prólogo y notas de Juan Millé y Giménez, Isabel Millé y Giménez. Madrid, Aguilar, 1956, pp. $157-158$ y $202-214$.

${ }^{21}$ Vid. LAPESA, obra cit., pp. 240-241. 


\section{DE LA POESÍA A LA HISTORIA, VIAJE DE IDA Y VUELTA}

En el episodio de las bodas de Camacho vuelve Cervantes a invocar los derechos de la historia, fiel reflejo de la verdad, frente a los fueros de la poesía, más atenta a las aspiraciones y esperanzas humanas.

La dicotomía aristotélica de Historia y Poesía encarna sus ecos poligónicos - $-\mathrm{y}$ tantas veces contradictorios- en las páginas del Quijote, como ya señalábamos hace tiempo ${ }^{22}$.

En el inicio de la Segunda Parte de la obra, replantea Sansón Carrasco la añeja distinción aristotélica, decididamente superada en la presente historia del ingenioso hidalgo manchego: «uno es escribir como poeta y otro como historiador: el poeta puede contar o cantar las cosas, no como fueron, sino como debían ser; y el historiador las ha de escribir, no como debían ser, sino como fueron, sin añadir ni quitar a la verdad cosa alguna» (II, 3).

En cuanto al episodio de las bodas de Camacho, nos encontramos, una vez más, con la síntesis y depuración de los dos ingredientes esenciales de la creación cervantina, el poético y el histórico, lo que es y lo que deber ser.

Partimos en el repetido episodio de una situación trágica, planteada por el mito poético de Ovidio: una tumba para dos amantes, inseparables incluso más allá de la muerte. Pero el autor moderno funde el ser con el deber ser y nos cuenta una historia concreta (con su ubi y el quando actuales) unida a la crónica de un caballero andante y soñador, siempre abierto a la esperanza y al triunfo de la vida. Claro está que en este caso las razones sociales y económicas de tanta fuerza histórica habían de ser anuladas por el amor, de gran ímpetu poético.

Quiere decirse que la distinción aristotélica solamente es admisible en una esfera especulativa y abstracta. Tarea inasequible resulta delinear, previa y exactamente, los perfiles y fronteras nítidas entre la historia y la poesía. El mito surge de la historia misma y a ella puede volver de forma imprevisible.

En otro tiempo nos sorprendió una afirmación inesperada en la pluma de un biólogo positivista, el Dr. Nóvoa Santos: «en última instancia, la Fantasía descubre la realidad, y se adelanta a ella, y la supera, e incluso la crea y la afianza» ${ }^{23}$.

\footnotetext{
22 Cfr. Alberto SÁnchez, "Historia y poesía en el Quijote», Cuadernos de Literatura, Inst. Miguel de Cervantes de Filología Hispánica, III; 1948, pp. 139-160.

23 Vid. R. Nóvoa Santos, La inmortalidad y los orígenes del sexo. Madrid, Biblioteca Nueva, 1931, p. 29. Es la última frase de un sabroso capítulo inicial que trata "Del ensueño y de la fantasía al mito".
} 
Karl Vossler pudo advertir certeramente que la concepción global del Quijote se apoya con firmeza en las relaciones de la historia y la poesía. La misma figura del caballero no es histórica, ni mítica o legendaria, sino poéticamente pura, ya que el conflicto no se decide ni a favor del hidalgo ni del escudero ${ }^{24}$.

Con todo, es cierto que como hidalgo de los tiempos modernos sintiera la nostalgia de un pretérito lejano, idealizado en los libros de caballerías, y le sugestionara «la imagen de una sociedad gobernada únicamente por las leyes del amor y del honor, de la lealtad y la justicia» ${ }^{25}$.

Podemos adivinar en el Quijote una trayectoria estética de ida y vuelta. Se parte de un mito poético, localizado en la antigua Babilonia, lejana en el espacio y en el tiempo; para trasladarnos ágilmente al escenario de la realidad histórica y actual del campo manchego, cercano y familiar. Pero al sobrevenir el agudo conflicto entre el Interés y el Amor, simbolizado entre flechas y tamborinos, por la «danza de Cupido» (II, 20), no vacilará el cronista en volver al punto de partida y proclamar la deseable victoria poética del Amor. Rápido viaje de ida y vuelta.

Maravillosa simbiosis de lo vivido y lo imaginado como preferible. Lo particular histórico y lo universal poético se han fundido armoniosamente en los lances y episodios de la narración.

ALBERTo SÁNCHEZ

${ }^{24}$ Cfr. K. Vossler, Introducción a la Literatura Española del Siglo de Oro. Madrid, Cruz y Raya, 1934.

25 Vid. VICENTE LlORENS, Aspectos sociales de la Literatura española. Madrid, Ed. Castalia, 1974, p. 63. 